\title{
Tsafon
}

Revue d'études juives du Nord

$82 \mid 2021$

Enjeux esthétiques dans la littérature après Auschwitz

\section{Berest Anne, La carte postale}

\section{Fabrice Danon}

\section{(2) OpenEdition}

Journals

Édition électronique

URL : https://journals.openedition.org/tsafon/4495

DOI : 10.4000/tsafon.4495

ISSN : 2609-6420

\section{Éditeur}

Association Jean-Marie Delmaire

\section{Édition imprimée}

Date de publication : 1 décembre 2021

Pagination : 148-150

ISSN : 1149-6630

\section{Référence électronique}

Fabrice Danon, « Berest Anne, La carte postale », Tsafon [En ligne], 82 | 2021, mis en ligne le 01

décembre 2021, consulté le 12 février 2022. URL : http://journals.openedition.org/tsafon/4495; DOI : https://doi.org/10.4000/tsafon.4495

Ce document a été généré automatiquement le 12 février 2022.

Tsafon. Revues d'études juives du Nord 


\title{
Berest Anne, La carte postale
}

\author{
Fabrice Danon
}

\section{RÉFÉRENCE}

Berest Anne, La carte postale, Paris, Grasset, 2021, 512 p. $24 €$.

1 Anne Berest, romancière, auteure (elle a consacré entre autres un livre à Françoise Sagan en 2014 et un autre - coécrit avec sa sœur Claire - à son arrière-grand-mère, Gabriële, épouse de Francis Picabia en 2017) a beaucoup fait parler d'elle cette année...

D'abord parce que son livre a figuré sur la liste finale pour le Goncourt, qu'il a été encensé par quelques critiques. Parce qu'ensuite il a été éreinté sans ménagement par Camille Laurens dans les colonnes du Monde.

3 Le récit commence le 6 janvier 2003 par la réception dans la boite aux lettres de la mère de l'auteure d'une carte postale, datant des années quatre-vingt-dix et comportant les seuls prénoms des grands-parents, oncle et tante de la mère d'Anne : Ephraïm, Emma, Noémie et Jacques. Tous sont morts assassinés à Auschwitz en 1942. Ni signature ni explication... Mauvaise plaisanterie, menace?

4 L'épisode est oublié quand dix ans plus tard, séjournant chez sa mère avant d'accoucher, Anne Bérest l'interroge.

5 C'est le début d'un long récit, objet du livre $1^{\mathrm{er}}$, intitulé « Terres promises ».

6 Cette histoire commence en Russie avec Ephraïm Rabinovitch, arrière-grand-père de l'auteure. Il quitte la Russie en 1919 avec sa femme, s'installe pour un temps à Riga (en Lettonie) où naît Noémie, en 1923 ; ils émigrent en Palestine puis s'installent enfin à Paris. Assimilation... Les enfants fréquentent les bons lycées parisiens, Ephraïm devient Eugène Rivoche, demande la nationalité française - qui lui est refusée - achète une maison de campagne en Normandie.

7 Mais les menaces se précisent: Hitler est devenu chancelier, la Tchécoslovaquie est annexée. La guerre est déclarée avec les lois anti-juives, l'exposition «Le Juif et la France $» .$. 
8 Myriam épouse Vincente (fils de Francis Picabia), échappe miraculeusement aux Allemands. Mais Jacques et Noémie sont arrêtés, emprisonnés à Evreux puis à Pithiviers avant d'être déportés à Auschwitz. Jacques est gazé. Noémie meurt peu après du typhus. Emma et Ephraïm sont arrêtés à leur tour, transférés à Drancy et gazés à Auschwitz le 7 novembre 1942.

La deuxième partie, intitulée "Souvenirs d'un enfant juif sans synagogue ", est consacrée aux interrogations de l'auteure, à ses conversations avec sa mère, à la poursuite de l'enquête (elle a fait appel à une agence de détectives privés, à un graphologue), à ses recherches en Normandie (dans la maison de campagne de ses parents).

10 Les troisième et quatrième parties sont consacrées à Myriam, la grand-mère de l'auteure, qui seule a échappé à la tragédie familiale. C'est l'occasion d'un (trop) long récit sur leur vie en Provence, au trio amoureux qu'elle constitue avec son mari et Yves, un ami. On y croise René Char, on continue de travailler pour la Résistance. Puis après le Débarquement, la libération de Paris, la naissance de Lélia (mère de l'auteure), les déportés reviennent. Myriam attend à l'hôtel Lutetia l'improbable retour de ses parents. En vain. Elle part pour l'Allemagne, à leur recherche. Elle confie sa petite fille à une vieille nourrice, en Provence. Après quelques années, elle s'y installe à son tour, perd peu à peu la mémoire.

11 À l'occasion de son quarantième anniversaire, plutôt qu'un séjour vinicole et une exposition en Provence, les souvenirs la rattrapent. Elle se rend à Céreste où la petite Lélia avait été mise en nourrice. C'est Mireille, une vieille femme de 90 ans, qui lui donnera la clef de l'énigme de la carte postale...

12 Si l'on passe sur la polémique déclenchée par l'article de Camille Laurens (qu'importe la cuisine littéraire, l'article est argumenté, rosse et souvent juste à mes yeux), l'ouvrage devrait laisser perplexes les lecteurs : il ne s'agit ni d'Histoire ni de témoignage même si Anne Berest s'est appuyée sur une vaste documentation.

13 Mais elle y mêle inventions personnelles, lettres privées, monologues et dialogues avec sa fille, sa mère, son compagnon - réflexions diverses (sur l'antisémitisme) et élucubrations (elle croit aux actes psychomagiques et aux "poches de temps ", cite à l'appui de ses dires Jodorowsky).

14 Un critique a inventé pour qualifier ce livre les mots de «thriller mémoriel », création curieuse et assez indécente au regard des sujets abordés. Le livre est aussi semé de pastiches, volontaires ou non (Giono et la vie provençale) ; le trio amoureux, souvenir de Jules et Jim de Pierre-Henri Roché ? L'auteur y abuse du name dropping (Irène Némirovsky, Walter Benjamin, Beckett, etc).

15 Tout ceci me paraît souvent irritant et déplacé en regard du sujet (la Shoah) ou de ce que l'auteure prétend avoir voulu mener (je cite la quatrième de couverture, c'est-àdire une " quête initiatique sur la signification du mot « Juif » dans une vie laïque »).

L'amateur de romans retournera à Gary ou Modiano par exemple. L'amateur de littérature se procurera l'ouvrage opportunément consacré par la Pléiade aux écrits des camps (Robert Antelme, Charlotte Delbo, Jorge Semprun, Jean Cayrol, Piotr Rawicz), paru en octobre dernier. 